\title{
MONOTONICITY AND SHARP INEQUALITIES RELATED TO GAMMA FUNCTION
}

\section{ZHEN-HANG YANG AND JINGFENG TIAN}

Abstract. In this paper, we investigate the monotonicity pattern of the function

$$
x \mapsto \frac{\ln \Gamma(x+1)}{\ln \left(x^{2}+a\right)-\ln (x+a)}
$$

on $(0,1)$ for $a \geqslant 1$ and resolve an open problem. From which we prove that the double inequality

$$
\left(\frac{x^{2}+a}{x+a}\right)^{(1-\gamma)(a+1)}<\Gamma(x+1)<\left(\frac{x^{2}+b}{x+b}\right)^{(1-\gamma)(b+1)}
$$

holds for $x \in(0,1)$ if and only if $0<a \leqslant(1-\gamma) /(2 \gamma-1)$ and $b \geqslant\left(\pi^{2}-6 \gamma\right) /\left(18-12 \gamma-\pi^{2}\right)$, while the double inequality

$$
\left(\frac{x^{2}+a}{x+a}\right)^{\gamma a}<\Gamma(x+1)<\left(\frac{x^{2}+b}{x+b}\right)^{\gamma b}
$$

holds for $x \in(0,1)$ if and only if $a \geqslant(1-\gamma) /(2 \gamma-1)$ and $0<b \leqslant 6 \gamma /\left(\pi^{2}-12 \gamma\right)$, where $\gamma=0.577 \ldots$ denotes Euler-Mascheroni's constant. These greatly improve some existing results. Mathematics subject classification (2010): Primary 33B15, 26A48, Secondary 26D15. Keywords and phrases: Gamma function, psi function, monotonicity.

\section{REFERENCES}

[1] M. Abramowitz And I. A. Stegun (Eds), Handbook of Mathematical Functions with Formulas, Graphs, and Mathematical Tables, National Bureau of Standards, Applied Mathematics Series 55, 9th printing, Washington, 1970.

[2] H. AlZer, Inequalities for the gamma function, Proc. Amer. Math. Soc., 128, (1) (1991), 141-147.

[3] H. Alzer, On some inequalities for the gamma and psi functions, Math. Comput., 66, (217) (1997), 373-389.

[4] G. D. Anderson, M. Vamanamurthy and M. Vuorinen, Monotonicity rules in calculus, Amer. Math. Monthly, 113, (9) (2006), 805-816.

[5] Á. BARICZ, Redheffer type inequality for Bessel functions, J. Inequal. Pure Appl. Math., 8, (1) (2007), Art. 11

[6] N. Elezović, C. Giordano And J. PeČarić, The best bounds in Gautschi's inequality, Math. Inequal. Appl., 3, (2) (2000), 239-252.

[7] P. IVÁDY, A note on a gamma function inequality, J. Math. Inequal., 3, (2) (2009), 227-236.

[8] P. KUPÁN AND R. SZÁsZ, Monotonicity theorems and inequalities for the gamma function, Math. Inequal. Appl., 17, (1) (2014), 149-159.

[9] A. Laforgia And P. Natalini, On some inequalities for the gamma function, Adv. Dyn. Syst. Appl., 8, (2) (2013), 261-267.

[10] I. PInelis, L'Hospital type rules for monotonicity, with applications, J. Inequal. Pure Appl. Math., 3, (1) (2002), Art. 5.

[11] I. Pinelis, On L'Hospital-type rules for monotonicity, J. Inequal. Pure Appl. Math., 7, (2) (2006), Art. 40. 
[12] F. QI, S. GuO AND B.-N. GuO, Complete monotonicity of some functions involving polygamma functions, J. Comput. Appl. Math., 233, (9) (2010), 2149-2160.

[13] ZH.-H. YANG, A new way to prove L'Hospital monotone rules with applications, arXiv:1409.6408 [math.CA].

[14] ZH.-H. YANG, Y.-M. CHU, AND X.-J. TAO, A double inequality for the trigamma function and its applications, Abstr. Appl. Anal., 2014 (2014), Art. ID 702718, 9 pages.

[15] ZH.-H. YANG, Y.-M. ChU AND X.-H. ZHANG, Sharp bounds for psi function, Appl. Math. Comput., 268 (2015), 1055-1063.

[16] J.-L. ZHAO, B.-N. GUO AND F. QI, A refinement of a double inequality for the gamma function, Publ. Math. Debrecen, 80, (3-4) (2012), 333-342.

[17] T.-H. ZhaO, ZH.-H. YANG AND Y.-M. ChU, Monotonicity properties of a function involving the psi function with applications, J. Inequal. Appl., 2015 (2015): 193. 